\title{
The Influence of Covid-19 on Perceived Health Effects of Wetland Parks in China
}

\author{
Xuezhu Zhai $^{1} \mathbb{D} \cdot$ Eckart Lange $^{1}$
}

Received: 12 July 2021 / Accepted: 8 October 2021 / Published online: 25 October 2021

(c) The Author(s) 2021

\begin{abstract}
Wetland parks are designed to support urban ecological protection, flood control and human well-being. Existing research mainly focuses on their influence on ecology and economy. However, their influence on human well-being and health is rarely studied. In China, during the peak of the COVID-19 pandemic (Peak), people were very concerned about health, while at the same time wetland parks which are generally considered beneficial to health were closed. Thus, this study explores the public's perception of the health effects of visiting wetland parks and the impact of the pandemic on the perception. From March 5th to 8th, 2020, before the Peak in China was over, 1,400 respondents participated in a nationwide online survey. It was found that the perceived benefits from visiting wetland parks were higher in terms of mental health than in physical health. Also, the perceived health benefits of wetland parks after the Peak were slightly higher than before the pandemic. The results highlight that wildlife habitat services were considered to be the most important ecosystem services that promote the perceived health benefits. Interestingly, the perceived health benefits of wetland parks by health experts appear to be lower than in other groups, indicating that the health benefits of visiting wetland parks may be overestimated by lay-people or underestimated by health experts. The results provide empirical evidence for managing ecosystem services as delivered by these urban wetlands, in the context of COVID-19 or potential future pandemics, for promoting public health.
\end{abstract}

Keywords Health $\cdot$ COVID-19 $\cdot$ Wetland park $\cdot$ Perception $\cdot$ Ecosystem services

\section{Background}

Urban dwellers in China experienced profound levels of anxiety and poor perceived health during the peak of the COVID-19 (Peak) (Ni et al. 2020), from January to March in 2020 (shown in Fig. 1). During the worst month of the Peak, many cities were locked down, and most parks were shut down. After February $17^{\text {th }}$, some employees started to return to work, but non-essential travel was not encouraged. After February $21^{\text {st }}$, when CHSLA (Chinese Society of Landscape Architecture (CHSLA) 2020) published a Group Standard for guiding operational management of urban parks during the pandemic, some parks began to reopen. Subject to compliance with the Standards, visitors were limited to $30-50 \%$

Xuezhu Zhai

xzhai4@sheffield.ac.uk

Eckart Lange

e.lange@sheffield.ac.uk

1 Department of Landscape Architecture, University of Sheffield, Western Bank, Sheffield S10 2TN, UK of the carrying capacity. Data for this study were collected from March $5^{\text {th }}$ to March $8^{\text {th }}$, when the curve of the pandemic dropped steeply and hit the bottom in terms of new confirmed cases. It was just a few days before the official announcement ${ }^{1}$ of the end of the Peak on March $12^{\text {nd }}$ (Zou 2020), when the case numbers were similar to the end of the Peak and most epidemic prevention measures were lifted.

\section{Wetland Parks, Health, and Human Well-being}

\section{Wetland Parks}

In this study, according to the Classification Standard for Urban Green Spaces (Ministry of Housing and Urban-Rural Development of the People's Republic of China (MOHURD) 2017), wetland parks (WPs) include not only ecological

\footnotetext{
1 The spokesperson of the National Health Commission of the People's Republic of China declared that "China has passed the climax of the novel coronavirus outbreak, with the number of new infections continuing to decline" on March 12nd,2020.
} 
Fig. 1 Timeline of the COVID19 in China (Data source: DX Doctor COVID-19 Pandemic Real-time Report), milestones relevant to this study, and the data collection period

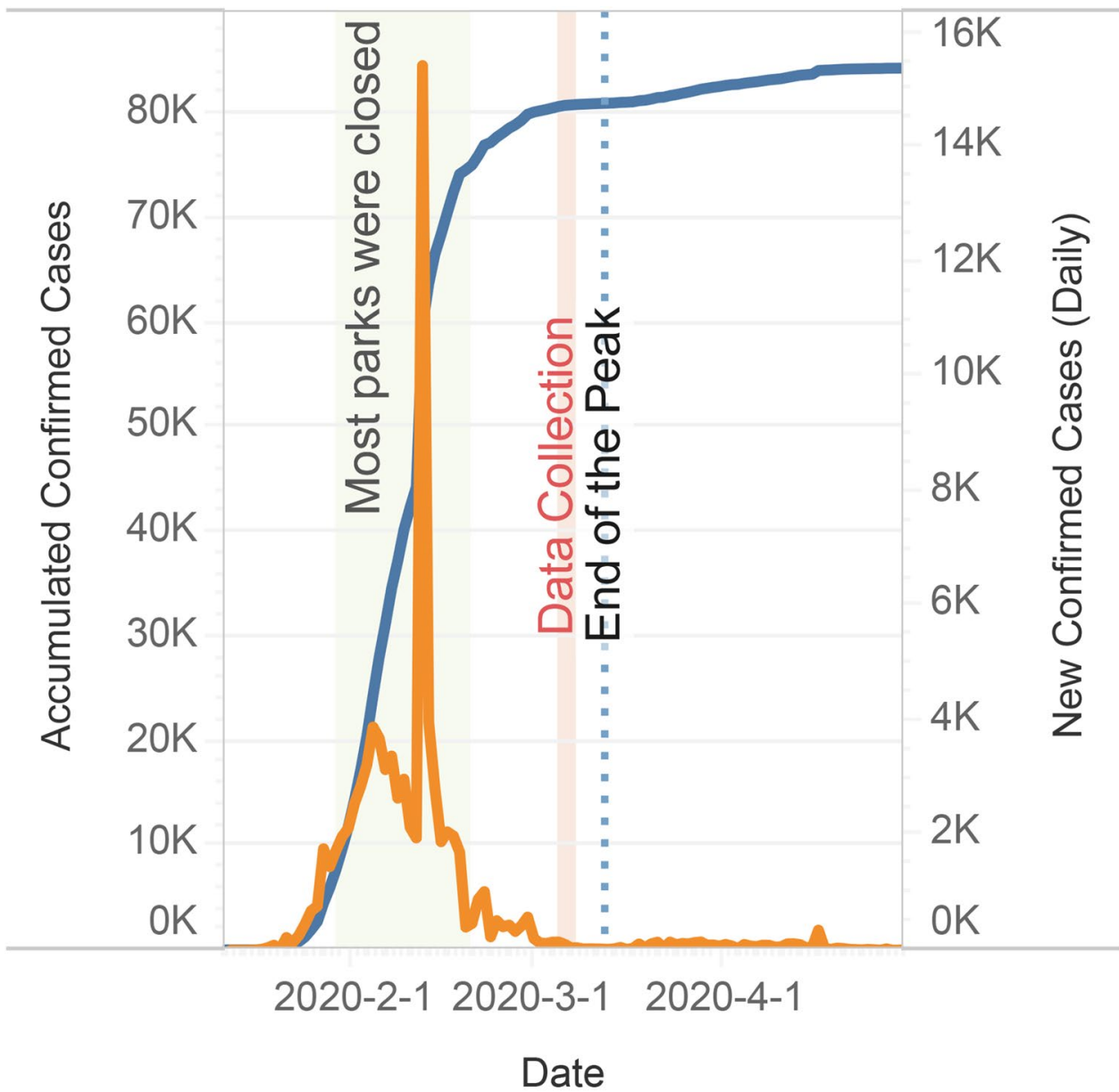

\section{LEGEND}

Accumulated Confirmed Cases

New Confirmed Cases (Daily) parks with "wetland parks" in the name but also public green spaces containing rivers, lakes and other wetlands.

\section{Health Effects of Wetland Parks and Ecosystem Services}

Many studies have shown that natural environments can be beneficial to physical and mental health. For example, exercising in natural environments brings higher levels of happiness than exercising in indoor and street environments (Bowler et al. 2010; Olafsdottir et al. 2017), 5]. Contact with nature could affect health in many ways, e.g. fresh air, physical exercise, social cohesion, and stress reduction (Hartig et al. 2014).

For most people living in cities, urban green spaces are the most (sometimes the only) accessible natural resource (Maller et al. 2010). Many scholars have evaluated the health effects of green spaces around the living environment, and found that (1) there is a positive or weak correlation between green space and obesity-related health (Lachowycz and Jones 2011); (2) the higher the ratio of green space in community, the lower the risks of mental health risks and cardiovascular disease (Richardson et al. 2013), and the higher the self-rated health status (Orban et al. 2017); (3) and the ratio of urban green space in a city is negatively correlated with the rate of local antidepressant prescriptions (Helbich et al. 2018). It also has been proved that urban green spaces can promote Chinese residents' physical activity so as to improve public health (Wang et al. 2019).

Urban blue space and proximity to water also promotes human health (Crouse et al. 2018). Specific to the wetland ecosystems, they can promote human well-being and health by provision of safe drinking water, improving resilience to natural disasters, and providing medicines; but it may also harm health by spreading diseases and releasing pollutants (Horwitz and Finlayson 2011).Besides, experiencing the physical and mental health benefits of healthy wetlands can offset some of 
the stress and illness associated with disasters such as flooding, drought, and wildfires (Sutton-Grier and Sandifer 2019). These health benefits can be attributed to ecosystem services (ESs) including provisioning, regulating and cultural, helping with e.g. malignant neoplasms, mental and behavioural disorders, and cardiovascular disease (Oosterbroek et al. 2016). Despite these fragmentary evidences, the health effects of WPs-a particular type of urban wetlands-are poorly understood, in particular regarding how they are perceived when visited and experienced. As Scholte et al. (2016) suggest, understanding how people interact with ecosystems is important to foster public support for wetland restoration; learning how the public perceive the health benefits from wetland parks could help with fostering public support for urban wetland restoration.

\section{Perceived Health Effects}

Urban environments and their perception significantly affect residents' self-evaluated health. Urban greening and infrastructure conditions are the main influencing factors (Wang et al. 2020). The expected benefits to human health, especially the expected improvement in psychological and social welfare, of visiting nature reserves are considered to be the main value of personal preference and choice of visiting nature reserves (Lemieux et al. 2012). Besides, people are increasingly aware of the positive relationship between visiting parks and nature reserves and related health benefits (Romagosa et al. 2015). Also, different people may have different perceptions of the health effects of the same environment, so it is of great significance to study the perception of the health effects of diverse populations.

\section{Aims}

The main aim of the research is to (1) explore the public's perception of the health effect of WPs before, during, and after the peak of the COVID-19 pandemic (Peak), and (2) explore the impact of the epidemic and other factors on people's perception of health effect of WPs.

\section{Methods}

\section{Data Collection: Online Questionnaire}

The data for the study was collected nationwide in China through online questionnaires using the Tencent Questionnaire platform. The differences in pandemic risks across provinces were used to study the impact of the epidemic on perceived health effects. The questionnaire was distributed using snowball sampling on the social media WeChat, which has the largest number of users in China (with 1.21 billion monthly active users in 2020) as the "seed", from March
5 th to 8 th, 2020. We set the sample size to 1400 (one out of 100,000 of the total population of China), considering that when the sample size increases to 1000 , the sharp increases in precision due to the growth of sample size becomes less pronounced (Bryman 2012). Also, after deducting non-wetland park users, the sample size could be large enough for a margin of error between 3 and 5 with a $95 \%$ confidence level. (Hazra 2017) Once the target number of total valid responses $(1,400)$ was reached, data collection was stopped. ${ }^{2}$

After collecting demographic data, questions of "whether you would like to visit a park/WPs after the pandemic is over?" ${ }^{3}$ were asked separately; the survey would continue if the respondents indicated a willingness to visit WPs. At the beginning of the questionnaire and in the note of each question include "WPs", the definition of WPs was given with examples of well-known WPs: The "wetland parks" in this survey include both ecological theme parks with "wetland parks" in their names (such as Hangzhou Xixi National Wetland Park, Suzhou Tai Lake National Wetland Park, Wuhan East Lake National Wetland Park, Guangzhou Nansha Wetland Park, etc.), as well as including parks dominated by wetlands such as rivers and lakes with good ecological functions (such as Shenzhen Dasha River Park, Guangzhou Lu Lake Park, Chengdu Living Water Park, etc.). Participants who were unwilling to visit parks and WPs were asked to give reasons, and then skip to the end of the survey.

For respondents who would like to visit WPs, questions about the frequency of visit before and after the pandemic were asked: (1)" If wetland parks were not closed during the epidemic, and your community and nearby roads were not closed, would you visit wetland parks?"; (2) "After the outbreak, how often do you think you will visit wetland parks?"; (3) "After the epidemic, what do you think is the reason why your frequency of visiting wetland parks would be increased or decreased (Please skip this question if you would not change your frequency of visits)?" The survey continued only when a respondent had been to wetland parks in the year before the outbreak. Also, respondents were asked to

\footnotetext{
2 We set the questionnaire distribution on the Tencent Questionnaire Platform to send automatic reminders for every 50 new responses, and manually checked and eliminated invalid questionnaires (such as questionnaires answered by children) simultaneously with the collection of questionnaires. We closed the questionnaire immediately after receiving 1,400 valid responses.

3 When the survey was conducted, the epidemic was expected to end by April 2020. However, this epidemic subsequently developed into a global pandemic and has not yet ended. Therefore, in the questionnaire, "during the epidemic" refers to the Peak, and "after the epidemic" and "when the epidemic is over" mean "after the Peak". Because the survey period was when this new coronavirus was first identified after it had spread throughout China, cities across the country have taken the same epidemic prevention measures at almost the
} same time. 
name their favourite WP, and reasons why this WP was preferred was asked using a multiple-choice question with an "others" option for the participants to respond.

These were followed by a set of questions about willingness to visit WPs during the Peak: (1) "If the wetland park was not closed during the epidemic, and your community and nearby roads were not closed, would you visit wetland park? (a single choice question)"; (2) "Whether the wetland park you usually go to, or you last visited has been reopened? (a single choice question)"; (3) (multiple choice question with "other" option only for respondents who chose the option "it has been opened orderly and you have been to" in the last question) "After the orderly opening of wetland parks, even the procedures are complicated, and masks are needed, why do you still visit the wetland parks?".

Other independent variables (influencing factors at four levels) and dependent variables (perceived health effects related to WPs) were collected, as described in the following sections. Respondents spent an average of 6.5 minutes filling out the questionnaire. Two rounds of pre-tests were conducted before March $5^{\text {th }}$ to ensure that respondents correctly understand the questionnaire.

\section{Dependent Variable: Perceived Health Effects Associated with Wetland Parks}

This study uses perceived health benefits or risks as dependent variables to characterize the impact of wetland parks on health perceived by citizens. A seven-point Likert Scale was used to evaluate the perceived mental and physical health effects of visiting WPs before, during, and after the Peak. Respondents were asked "Before/During/After the Peak, what do you think will be the impact of visiting WPs on your physical/mental health?" respectively.

\section{Independent Variables: Factors of Perceived Health Effects}

This study included four levels of variables, namely city, community, WPs, and individual levels.

\section{City Level}

During the Peak, the severity of the epidemic situation (i.e., the numbers of cumulative confirmed cases, newly confirmed cases and deaths) varied among provinces and cities in China, leading to different epidemic risks and emergency policies. These may affect the perceived health effects of wetland parks. The Response Level to Public Health Emergency (RLPHE) in a given region on a single day can reflect the risk level of an outbreak in that region on that day. The investigation period was at the end of the Peak, and some areas where the outbreak was not severe (i.e., there were not many confirmed cases and there had been no newly confirmed cases for a while) have lowered the RLPHE.

By asking about the main cities of residence at the peak of the epidemic, and according to the RLPHE of all provinces and cities across the country on March $6^{\text {th }}$ (midpoint in the sampling period), these cities were classified into three categories: first-level response, namely the highest risk; second-level response, high risk; third-level response, medium risk.

\section{Community Level}

During the Peak, many communities in cities with higher epidemic risk levels were locked down. Some communities were entirely locked down, and quarantine was required. Some communities were semi locked down, where residents could leave their homes and do activities in the communities, but could not go out of the community unless necessary. In low-risk cities, the communities were not closed. Information on the degree of community lockdown during the Peak was collected using a single-choice question.

\section{WPs Level}

Health Effects of Wetland Parks Respondents were asked about the name of the wetland park they often visited or their favourite and why they like this WP. The wetland parks that the participants visited most or their favourites were coded according to the main wetland types they contain (e.g., lakes, rivers, coast, swamp), and the correlation analysis of preferred wetland types in the same corresponding level of regions with health effect perception (measured in "Dependent Variable: Perceived Health Effects Associated with Wetland Parks" section) was carried out to study the perceived health effects of preferred wetland types.

Health Effects of Ecosystem Services This study explored the perceived ESs from wetland parks and the health effect of these perceived ESs, by asking participants to make multiple choices for perceived ESs first, and then ranking their choices according to importance to the improvement of their physical and mental health. ESs including habitat, water purification, air purification, noise reduction, flood regulation, recreation, aesthetics, education, and social relations were involved. These examined ESs were selected according to previous studies on perceived ESs in WPs (Zhai and Lange 2020). They belonged to the regulating, cultural and supporting category. The provisioning services were not examined in this study because WPs do not always deliver provisioning services (e.g., food, raw materials). 


\section{Individual Level}

This part first collected the respondents' socio-demographic details (such as age, gender, highest education level, professional, occupation status, and city of residence) through five single-choice questions and two drop-down questions. Respondents' self-reported physical and mental health status before and during the Peak was then collected through four five-point Likert scale questions.

\section{Data Analysis}

All statistical analyses were performed using SPSS Statistics 25 . Descriptive statistics were used to analyze the respondents' profiles. The open-ended questions were coded for descriptive statistics. Analysis of variance (ANOVA) and one-way T-test were used to examine whether various factors affect perceived health effects. Bivariate correlation analysis was used to study the correlation between self-reported health status and perceived health effects.

\section{Results}

\section{Respondents' Profiles}

The majority of the respondents were young and middleaged $(65.43 \%$ of respondents were younger than 34 years old) and have a high level of education (graduate or higher) (Table 1). 57.9\% of the respondents were females. 63.0\% of the respondents were employed, $27.8 \%$ were students, and others were retired or unemployed. $43.2 \%$ were engaged in architecture and built environment, and $6.14 \%$ were health experts (i.e., medical and nursing or psychology professionals). Respondents came from 31 provinces including 161 cities, and were evenly distributed in cities with the three levels of RLPHE (Fig. 2). During the Peak, $75.3 \%$ of the respondents lived in semi-lockdown communities, $18.8 \%$ were quarantined at home, and $5.9 \%$ had free access to their homes and communities.

\section{Willingness to Visit Wetland Parks}

$81.6 \%$ of the respondents were willing to visit parks after the Peak $(\mathrm{N}=1142) .76 .9 \%$ of those who wanted to visit parks also wished to visit WPs $(\mathrm{N}=1077)$. The main reasons for not visiting WPs were poor accessibility (52.3\%). After the Peak, $28.2 \%$ of the respondents would increase their visiting frequency, while $55.3 \%$ of respondents would keep their visiting frequency (Fig. 3). Among the 1077 respondents who wished to visit WPs, 110 respondents had not been to wetland parks in the year before the outbreak. Considering that those 110 respondents may not be familiar with WPs,
Table 1 Respondents' profile

\begin{tabular}{|c|c|c|c|}
\hline & $\mathrm{N}=1400$ & $(\%)$ & 2010 Census $(\%)$ \\
\hline \multicolumn{4}{|l|}{ Age } \\
\hline $18-24$ & 362 & 25.86 & 15.31 \\
\hline $25-34$ & 554 & 39.57 & 18.21 \\
\hline $35-44$ & 232 & 16.57 & 19.21 \\
\hline $45-54$ & 174 & 12.43 & 14.03 \\
\hline $55-64$ & 65 & 4.64 & 9.34 \\
\hline$\geq 65$ & 13 & 0.93 & 7.68 \\
\hline \multicolumn{4}{|l|}{ Gender } \\
\hline Male & 590 & 42.14 & 51.14 \\
\hline Female & 810 & 57.86 & 48.86 \\
\hline \multicolumn{4}{|l|}{ Highest Education Level } \\
\hline Junior high school and below & 20 & 1.43 & 46.56 \\
\hline High school equivalent & 80 & 5.71 & 22.43 \\
\hline Specialized college & 118 & 8.43 & 11.65 \\
\hline Bachelor's & 655 & 46.79 & 9.37 \\
\hline Master's and above & 527 & 37.64 & 1.02 \\
\hline \multicolumn{4}{|l|}{ Occupation Status } \\
\hline Student & 389 & 27.79 & - \\
\hline Employee & 882 & 63 & - \\
\hline No occupation & 62 & 4.43 & - \\
\hline Retiree & 67 & 4.79 & - \\
\hline \multicolumn{4}{|l|}{ Professional } \\
\hline $\begin{array}{l}\text { Architecture \& built environ- } \\
\text { ment }\end{array}$ & 605 & 43.21 & \\
\hline Art \& design & 129 & 9.21 & \\
\hline Hydrology & 21 & 1.5 & \\
\hline Psychology & 14 & 1 & \\
\hline Medicine, nursing & 72 & 5.14 & \\
\hline Agriculture/forestry & 56 & 4 & \\
\hline Environmental science & 27 & 1.93 & \\
\hline Social science & 73 & 5.21 & \\
\hline Economy \& finance & 60 & 4.29 & \\
\hline Others & 343 & 24.5 & \\
\hline \multicolumn{4}{|l|}{ RLPHE of main place of residence } \\
\hline 1st level & 473 & 33.79 & $34.32 \%$ \\
\hline 2nd level & 392 & 28.00 & $50.38 \%$ \\
\hline 3rd level & 530 & 37.86 & $15.31 \%$ \\
\hline \multicolumn{4}{|l|}{ Community closure status } \\
\hline Totally lockdown & 263 & 18.79 & - \\
\hline Semi lockdown & 1054 & 75.29 & - \\
\hline Not lockdown & 83 & 5.93 & - \\
\hline
\end{tabular}

2010 Census means the population census of the People's Republic of China in 2010, to show the representativeness of the samples. Data source: National Bureau of Statistics of People's Republic of China. Although it is known that the online population is usually different from the total population, which makes it difficult for the online questionnaire sample to represent the total population, we have compared the demographic information of the sample with the national census to understand the difference between the sample and the total population 
Fig. 2 Geographical distribution of respondents

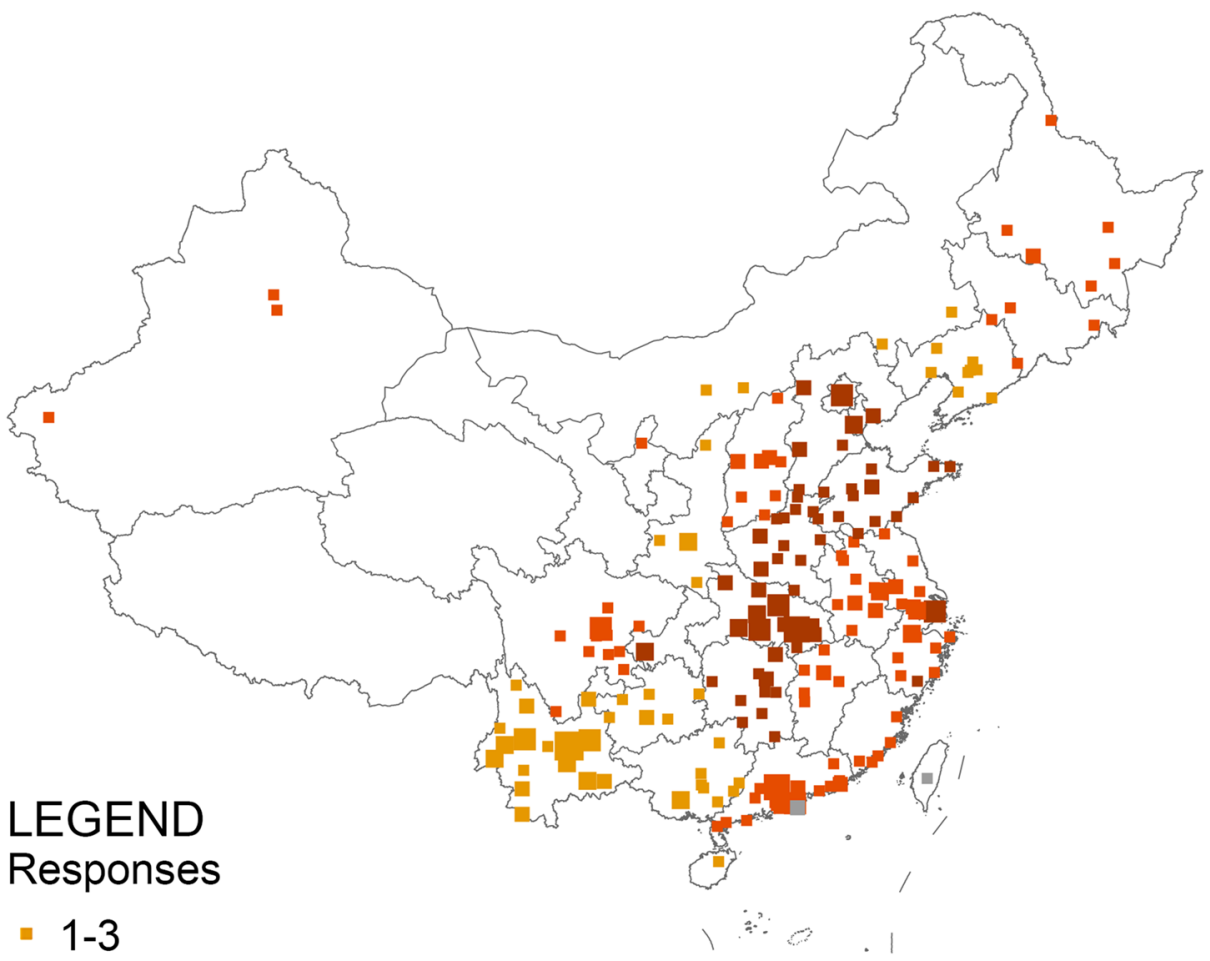

- $1-3$

4-7

8-17

$18-49$

$50-167$

168-301

\begin{tabular}{lrr} 
& after the Peak & $\begin{array}{c}\text { in the year before } \\
\text { the Peak }\end{array}$ \\
\hline $\begin{array}{l}\text { never been there } \\
\text { once in more than half a year }\end{array}$ & 252 & 110 \\
once every 4-6 months & 144 & 301 \\
once every 2-3 months & 212 & 139 \\
once a month & 147 & 199 \\
2-3 times a month & 165 & 121 \\
multiple times a week & 47 & 165 \\
\hline & & 42 \\
Frequency of visits (Count) & & \\
42 & & 301
\end{tabular}

(a)

(b) in the year before the Peak, expected after the Peak, and the change

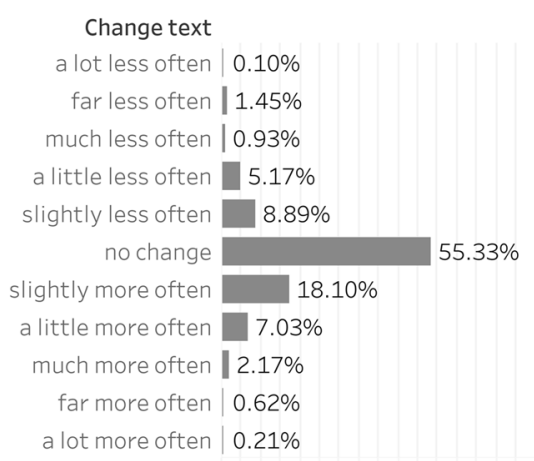

0 $150 \quad 300 \quad 450 \quad 600 \quad 750$

Count they were excluded from the following sections of survey. Thus, there were 967 respondents in total who took part in the whole survey (Fig. 4).

A total of 109 respondents had visited WPs (e.g., Fig. 5) since they reopened after the peak of the epidemic within two weeks. Fresh air (57.8\%), physical exercise
(43.1\%), and exposure to nature and wildlife habitats (42.2\%) were the main motivations. 'WPs are sparsely populated with low risk of infection' (36.7\%), 'Basking in the sun and enjoy the breeze' (35.8\%) and 'enjoy the beautiful scenery' (29.4\%) were important driving factors. 


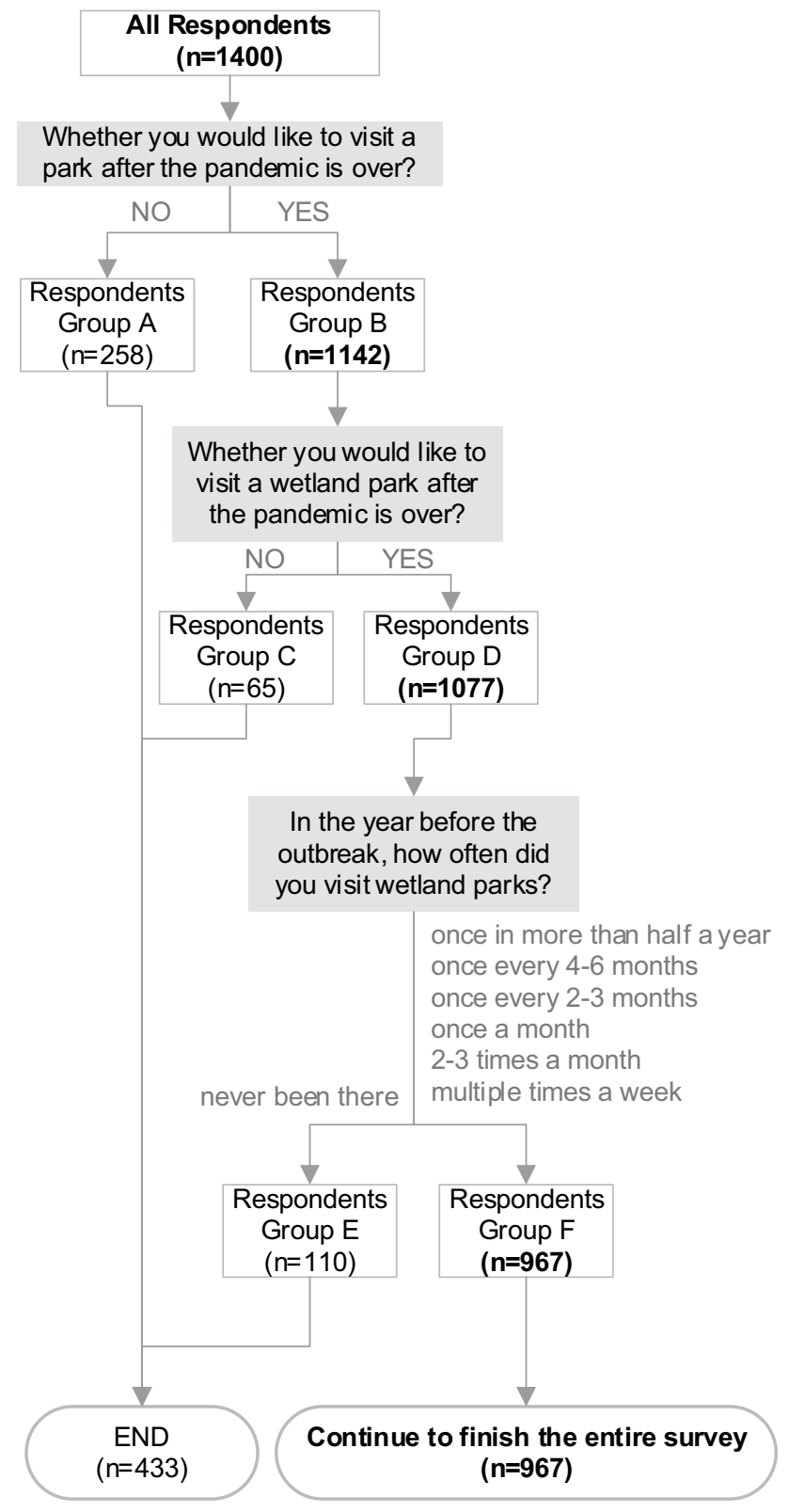

Fig. 4 Responses filters

\section{Dependent Variables: Perceived Health Effects}

The set of health-relevant scale items passed the reliability test $($ Cronbach's alpha $=0.797)$ and the validity test $(\mathrm{KMO}$ measure of sampling was adequate $(=0.732)$, and Bartlett's test of sphericity was significant $(\mathrm{P}=0.000))$. The results (Fig. 6) show that people perceive health benefits from WPs; even during the peak of the epidemic when the perceived benefits were the lowest, benefits still outweigh potential risks. The perceived benefits of visiting wetland parks on mental health were higher than that on physical health, especially during the peak of the epidemic. The perceived health benefits expected after the Peak were slightly higher than before the Peak: approximately $70 \%$ of the respondents perceived the same level of health effects from WPs before and after the Peak; about $20 \%$ of the respondents believed that health benefits have increased after the Peak; in contrast, about $10 \%$ of the respondents assumed that perceived health benefits decreased.

\section{Independent Variables}

\section{City Level}

As shown in Table 2, the RLPHE of the city of residence had a significant impact on the perceived physical and mental health benefits during the Peak and on the perceived mental health benefits after the Peak $(\mathrm{P}<0.05)$. Respondents in the second RLPHE regions perceived the highest health benefits, and those in the first RLPHE areas (the highest-risk area) perceived the lowest physical health benefits during the Peak and the lowest mental health benefits after the Peak. In contrast, respondents in third RLPHE regions (medium-risk areas) perceived the lowest mental health benefits during the Peak. On average, the perceived health benefits from WPs after the Peak were slightly higher than before the outbreak in all the three types of regions, but there was no significant difference in the change of perceived health benefits in these regions.

\section{Community Level}

The lockdown level of the respondents' community during the Peak had a significant impact on the perceived physical and mental health benefits after the peak of the epidemic $(\mathrm{P}<0.01)$ (Table 2). Surprisingly, as the degree of community lockdown level increased, the expected perceived physical and mental health benefits after the peak of the epidemic decreased. Because community lockdown occurred after the outbreak, the differences in the perceived level of mental health benefits before the Peak was not considered to be caused by community lockdown.

\section{Wetland Parks Level}

ESs for Promoting Perceived Health Benefits Most respondents thought that WPs provided habitat, recreation, air purification, and water purification services (Fig. 7a). Habitat and water purification were the two ESs that respondents rated as having the greatest perceived physical and mental health benefits (habitat ranked the first and water purification ranked the second. Air purification was essential for physical health, and recreation was important for mental health (Fig. 7b, c). Education and social relations were least important for promoting perceived health benefits. 


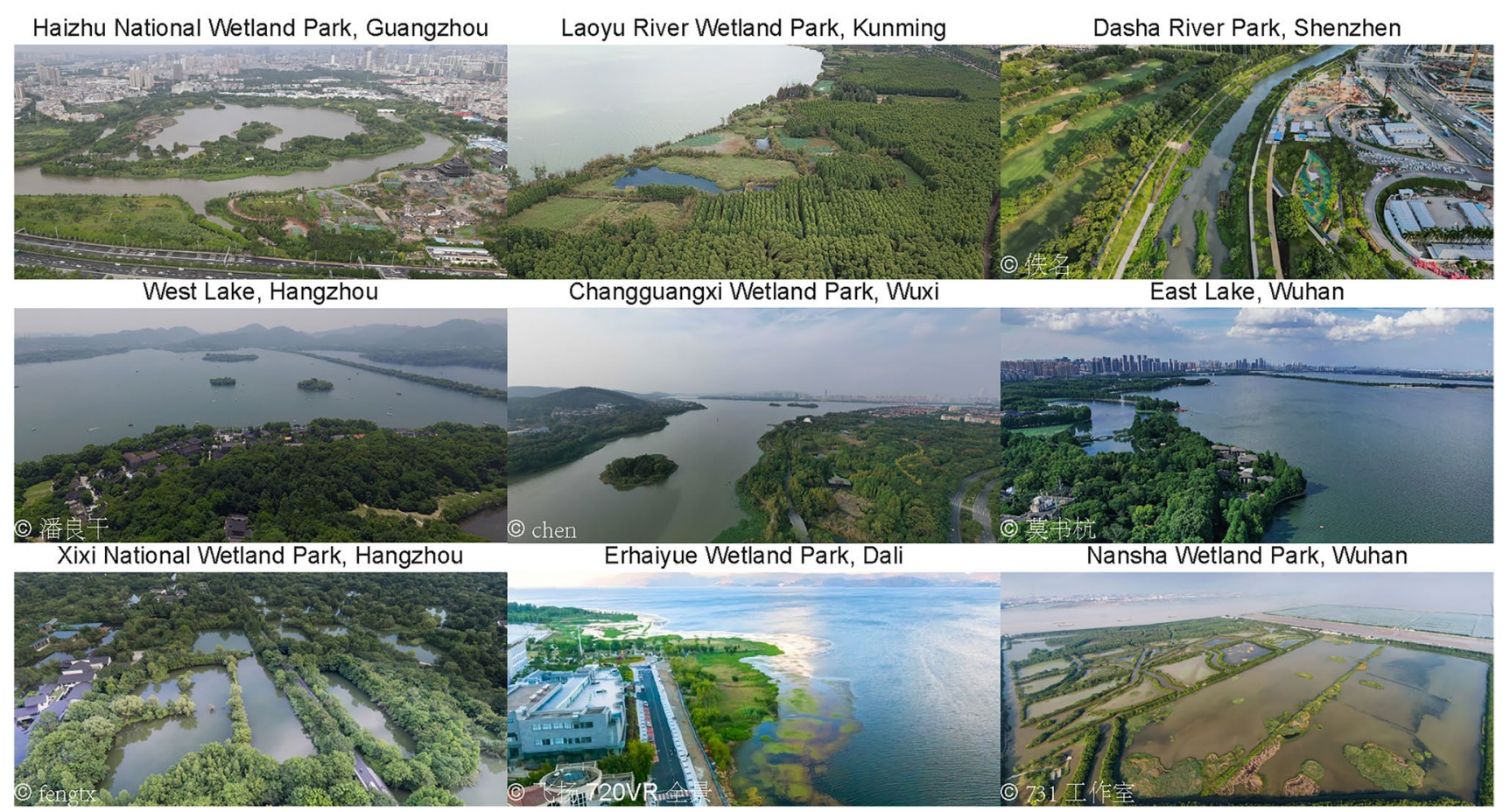

Fig. 5 Wetland parks that respondents mentioned most frequently. (Pictures marked with copyright are source from: www.720yun.com)

Wetland Types Lake was the most popular type among the different wetland types in WPs. Wetland types did not influence the perception of health effects, except for the perception of physical health effects before the Peak and mental health effects during the Peak in regions with the $2^{\text {nd }}$ level RLPHE (Table 3).

\section{Individual Level}

As shown in Table 4, the 45-54 age group perceived the highest physical and mental health benefits, while the 18-24 age group perceived the lowest physical and mental health benefits $(\mathrm{P}<0.05)$. Men perceived higher health benefits than women $(\mathrm{P}<0.05)$. Education levels and occupational status had no influence on the perceived health effects level before, during and after the Peak. There is a significant difference in the change of perceived health benefits before and after the Peak among various occupational status: compared with before the Peak, the temporarily unemployed and retirees perceived higher mental health benefits than the other two groups after the Peak $(\mathrm{P}<0.05)$.

Groups with various professional backgrounds had significant differences in the perceived health benefits before the epidemic $(\mathrm{P}<0.05)$; groups with environmental science backgrounds had the highest level of perceived health benefits. In addition, health experts (i.e., persons with medical, nursing, and psychology backgrounds) had significantly lower perceptions of mental health benefits before the epidemic and physical and mental health benefits after the Peak than other professional groups $(\mathrm{P}<0.05)$. Meanwhile, health experts believed that the health benefits after the Peak were slightly lower than those before the epidemic, which was opposite to other groups of people.

The self-reported physical health status before the epidemic was positively correlated with the perceived physical health benefits before the Peak (Pearson correlation $=0.06$, $\mathrm{P}<0.05$, see Table 5). The perceived physical or mental health benefits during and after the Peak were not statistically correlated with the self-reported physical or mental health status on the survey day. Also, the change of perceived health benefits was not statistically correlated with the change of self-reported health status.

\section{Discussion}

In general, the public perceives wetlands to be beneficial for physical and mental health, which is consistent with the conclusion of previous studies that urban green space and blue-green space are beneficial to people's physical and mental health (see "Health Effects of Wetland Parks and Ecosystem Services" section). A possible reason for the lowest perceived health benefits during the Peak could be the higher risk of infection. Limited access to WPs during the Peak could also contribute to the low perception of health 


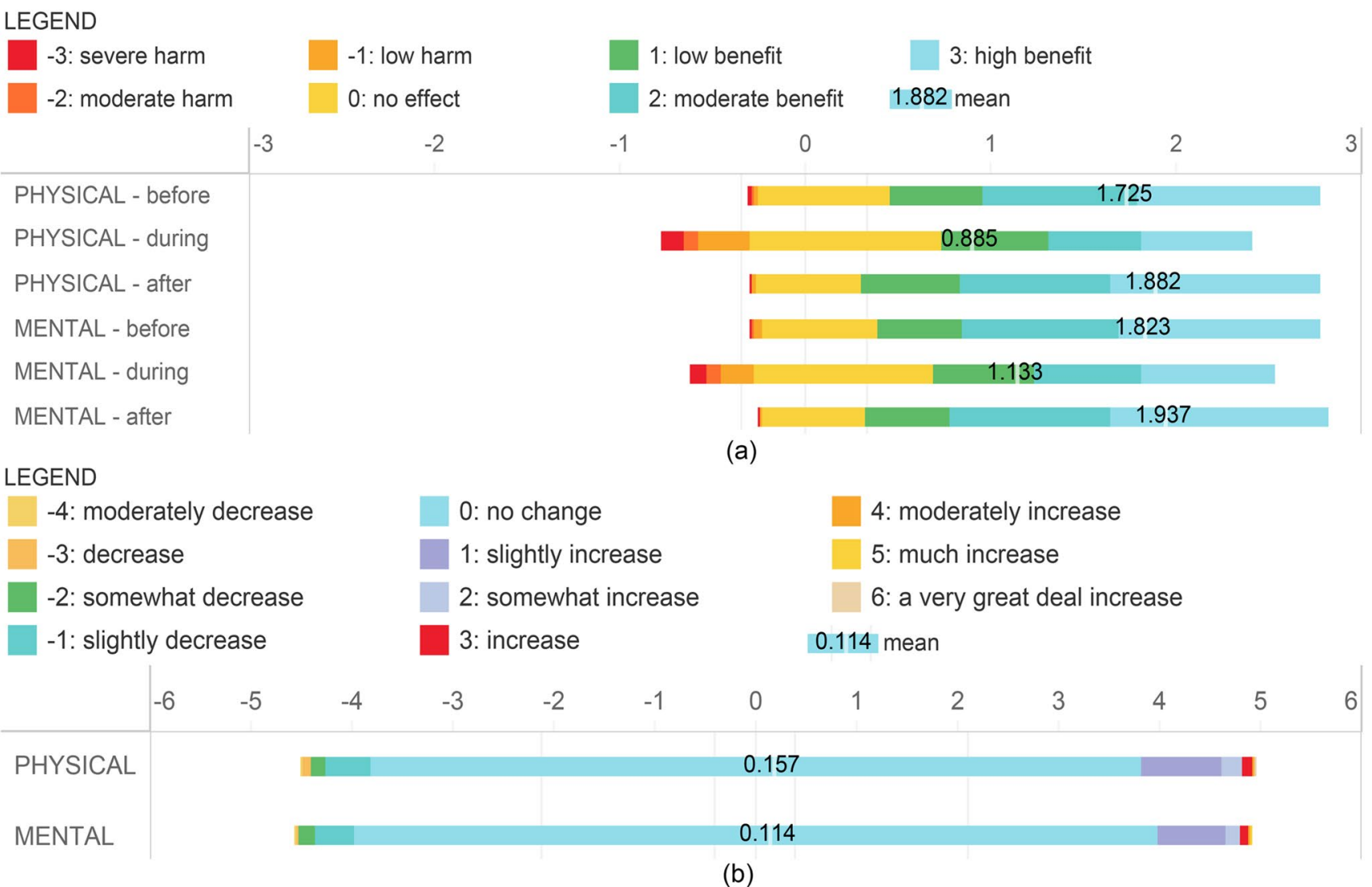

Fig. 6 Perceived health benefit before, during and after the peak of the COVID-19 outbreak. Divergent Stacked Bar: The length of each colour represents the proportion of respondents who chose this atti- tude to the total number of respondents. The starting point of each bar graph is different, and the total length is $100 \%$

Table 2 Impact of the factors (city and community level) $(*: \mathrm{P}<0.05, * *: \mathrm{P}<0.01)$

\begin{tabular}{|c|c|c|c|c|c|c|c|c|c|}
\hline & \multirow[t]{2}{*}{$\mathrm{N}=967$} & \multicolumn{2}{|l|}{ Before Peak } & \multicolumn{2}{|l|}{ During Peak } & \multicolumn{2}{|l|}{ After Peak } & \multicolumn{2}{|c|}{$\frac{\text { Difference: }}{\text { After-before Peak }}$} \\
\hline & & Physical & Mental & Physical & Mental & Physical & Mental & Physical & Mental \\
\hline \multicolumn{10}{|c|}{ CITY LEVEL: RLPHE of main place of residence } \\
\hline 1st level & 314 & $1.63 \pm 1.28$ & $1.71 \pm 1.24$ & $0.79 \pm 1.56$ & $1.09 \pm 1.50$ & $1.81 \pm 1.18$ & $1.87 \pm 1.18$ & $0.18 \pm 1.13$ & $0.16 \pm 0.89$ \\
\hline 2nd level & 260 & $1.82 \pm 1.20$ & $1.97 \pm 1.13$ & $1.12 \pm 1.55$ & $1.43 \pm 1.43$ & $2.01 \pm 1.10$ & $2.08 \pm 1.04$ & $0.19 \pm 1.03$ & $0.12 \pm 0.87$ \\
\hline 3rd level & 389 & $1.74 \pm 1.25$ & $1.82 \pm 1.25$ & $0.81 \pm 1.58$ & $0.97 \pm 1.60$ & $1.86 \pm 1.67$ & $1.90 \pm 1.15$ & $0.12 \pm 0.96$ & $0.08 \pm 0.89$ \\
\hline \multirow[t]{2}{*}{ One-way ANOVA } & $\mathrm{F}$ & 1.73 & 3.145 & 3.864 & 7.167 & 2.413 & 3.059 & 0.406 & 0.7 \\
\hline & $\mathrm{P}$ & 0.178 & 0.043 & $0.021 *$ & $0.001 * *$ & 0.09 & $0.047^{*}$ & 0.666 & 0.497 \\
\hline \multicolumn{10}{|c|}{ COMMUNITY LEVEL: Community closure status } \\
\hline Totally lockdown & 178 & $1.58 \pm 1.30$ & $1.60 \pm 1.31$ & $0.83 \pm 1.63$ & $1.12 \pm 1.49$ & $1.67 \pm 1.25$ & $1.70 \pm 1.24$ & $0.09 \pm 1.05$ & $0.10 \pm 0.95$ \\
\hline Semi lockdown & 732 & $1.75 \pm 1.23$ & $1.86 \pm 1.19$ & $0.88 \pm 1.56$ & $1.14 \pm 1.54$ & $1.91 \pm 1.14$ & $1.98 \pm 1.11$ & $0.16 \pm 1.04$ & $0.11 \pm 0.86$ \\
\hline Not lockdown & 57 & $1.81 \pm 1.25$ & $2.00 \pm 1.18$ & $1.09 \pm 1.57$ & $1.09 \pm 1.53$ & $2.19 \pm 0.99$ & $2.19 \pm 0.99$ & $0.39 \pm 0.92$ & $0.19 \pm 0.91$ \\
\hline \multirow[t]{2}{*}{ one-way ANOVA } & $\mathrm{F}$ & 1.442 & 3.994 & 0.601 & 0.035 & 5.202 & 5.917 & 1.774 & 0.27 \\
\hline & $\mathrm{P}$ & 0.237 & $0.019^{*}$ & 0.548 & 0.966 & $0.006^{* *}$ & $0.003 * *$ & 0.17 & 0.764 \\
\hline
\end{tabular}


(a)

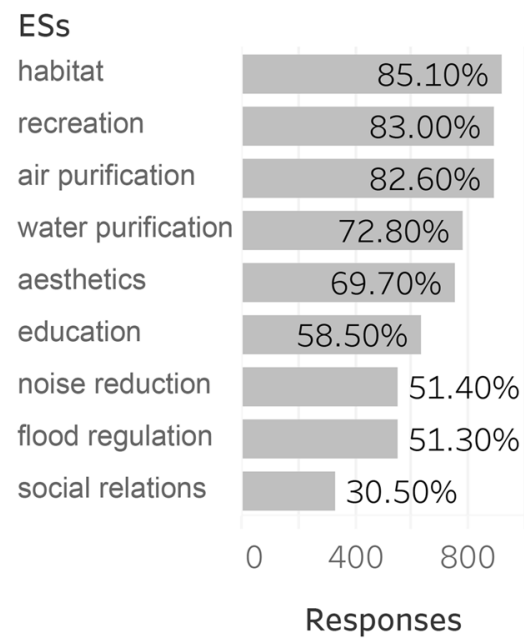

The percentage represents the proportion of responses that perceive a particular ecosystem service in the total number of responses. (b)

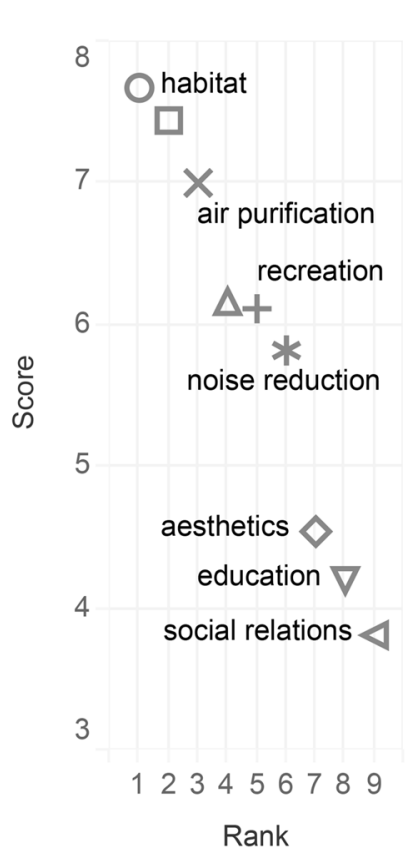

(c)

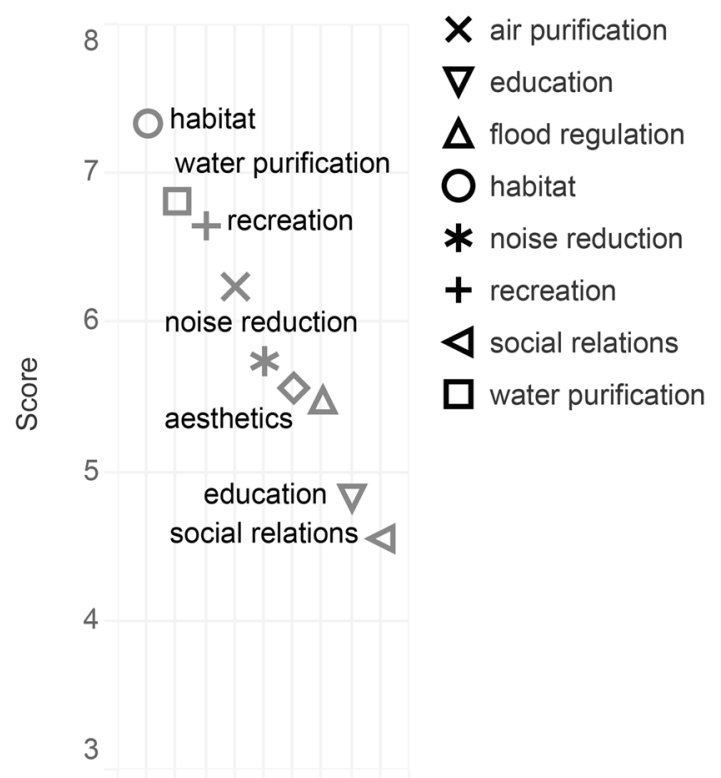

123456789

Rank

Fig. 7 Perceived ESs in WPs and ranking of their importance for promoting health benefits perception

benefits. The increase in perceived health benefits after the Peak shows that inaccessibility to WPs for a period of time may improve perceived health benefits from WPs.

On the city level, results show that a moderate epidemic risk stimulates perception of physical and mental health benefits from WPs. Further investigation regarding health benefits and harm perception associated with epidemic risks is needed to draw more precise recommendations for further improvement of WPs from the perspective of public health.

On the community level, unexpectedly, the perceived level of physical and mental health benefits after the Peak is negatively associated with the lockdown degree of the community, suggesting that quarantine did not lead to an increase in health-related motivation for visiting WPs.

In terms of WPs level, habitat services were considered to be the most important ecosystem services that promote the perceived health benefits. The possible reasons are: (1) self-reported happiness is positively correlated with the perceived species richness of birds, butterflies, and plants (Dallimer et al. 2012); (2) the biologically diverse natural environment can improve health by exposure to a pleasant environment or encouraging health promotion behaviours (Lovell et al. 2014); (3) there is a strong positive correlation between vegetation cover and personal well-being. The relationship between human well-being and nature is weakly correlated with changes in species richness, bird abundance, and plant density (Luck et al. 2011). However, habitat services were regarded as indirect health-related ES that affect human health through another service, and the mechanism of their effect on health is still unclear. The importance of habitat, air purification and recreation services align with the motivation for visiting WPs (e.g., being close to nature and wildlife habitat, enjoying fresh air and going out for exercises).

On the individual level, this study has found that men perceive higher health benefits than women when visiting urban blue-green spaces during the Peak. There is no significant gender difference before and after the epidemic. This is different from the result of a previous study based on two of Canada's blue-green spaces that women usually perceive higher health well-being than men from visiting nature reserves (Lemieux et al. 2012). The phenomenon that housewives and the elderly are more dependent on the local environment and therefore are more susceptible to the local environment (de Vries et al. 2003) could be a possible explanation to our result that the temporarily unemployed (e.g. housewives) and retirees (e.g. the elderly) perceived higher mental health benefits than the other two groups after the Peak. In addition, health experts' perception of mental health benefits before the epidemic and that of physical and mental health after the Peak were significantly lower than other professional groups, which indicate that lay people may have overestimated or health experts may have underestimated the health benefits of visiting WPs. Besides, health 
Table 3 Impact of the factors (wetland parks level) $(*: \mathrm{P}<0.05, * *: \mathrm{P}<0.01)$

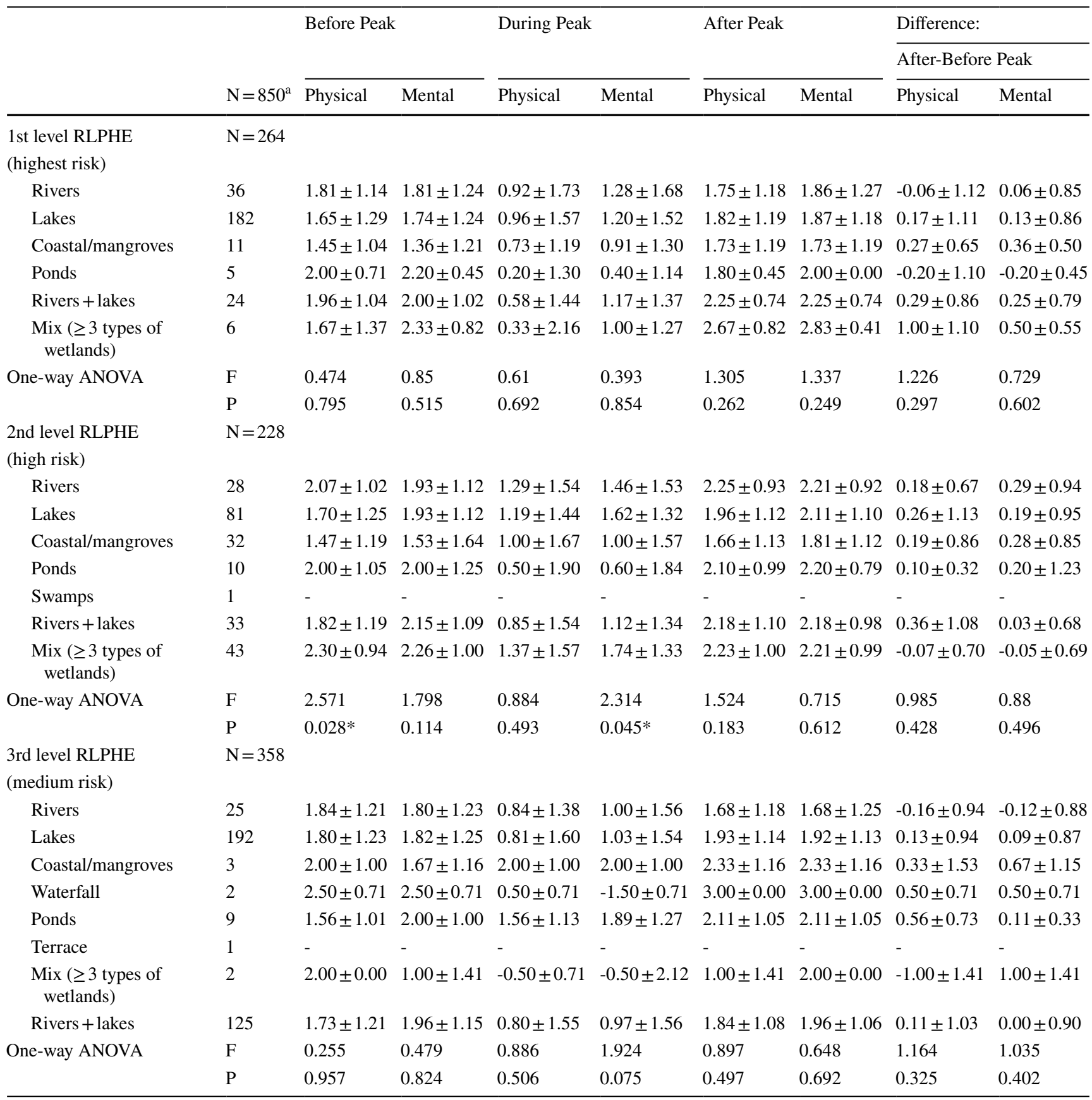

${ }^{a}$ The names of WPs filled by some respondents failed to be found online due to typos or unclear descriptions. These responses were not included in this part of analysis

experts believe that the health benefits after the peak of the epidemic are slightly lower than before the outbreak, while other people have the opposite view. This may be because health experts believe that travel after the peak of the epidemic poses a higher risk.

This study is based on a large number of subjective responses regarding the perceived health effects of WPs. It does not objectively measure the health effects of WPs.
Ecosystem disservices could negatively affect the perception of health benefits. For conducting the questionnaire, it was the assumption that there is little risk of infection by COVID-19 when visiting wetland parks after the Peak, which naturally excludes the effect of some infectious disease-related ecosystem disservices on health perception. Moreover, factors such as the quality, area, and naturalness of the WPs may affect health (Ekkel and de Vries 2017), 
Table 4 Impact of the factors (individual level) $(*$ : $\mathrm{P}<0.05, * *: \mathrm{P}<0.01)$

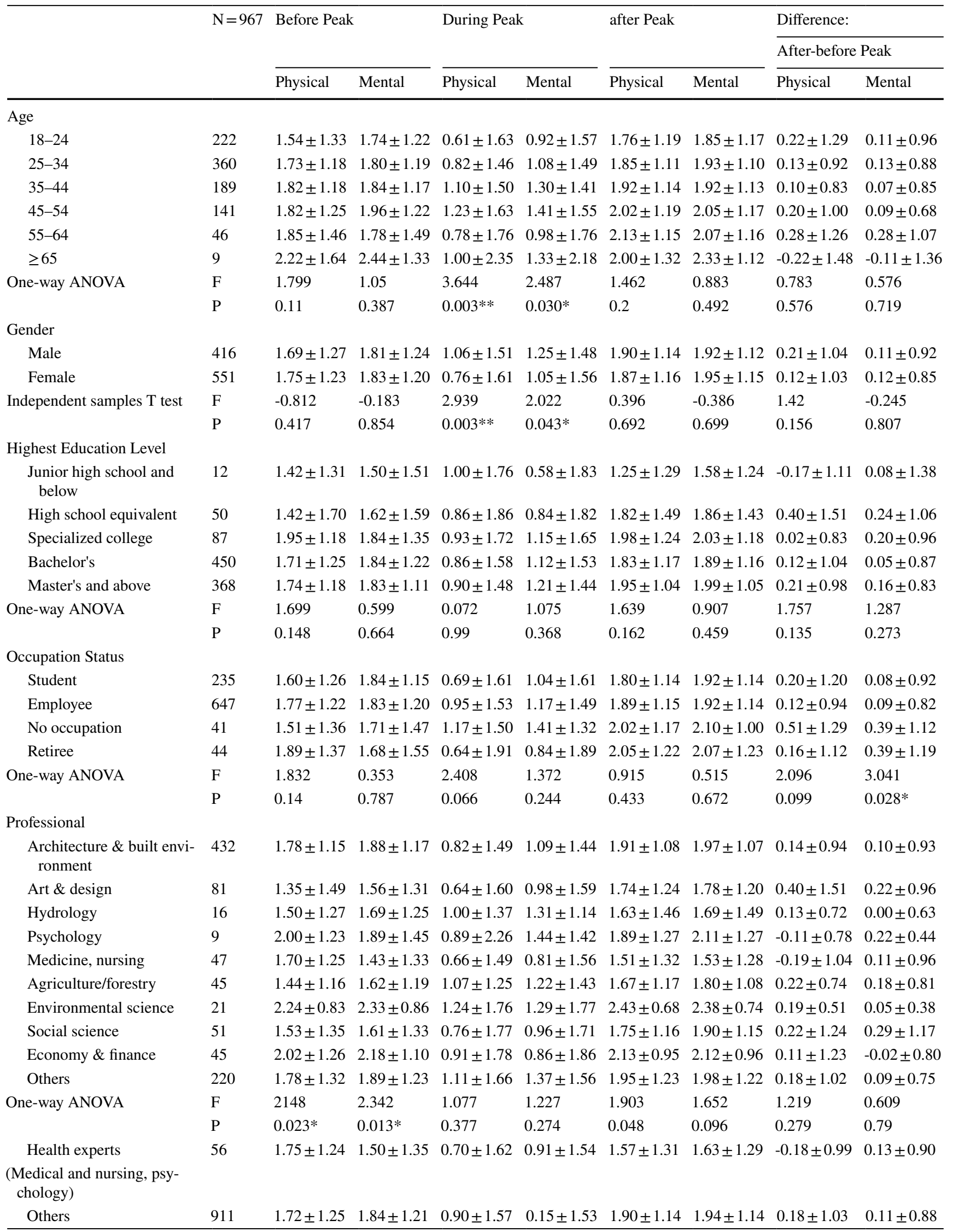


Table 4 (continued)

\begin{tabular}{|c|c|c|c|c|c|c|c|c|c|}
\hline & \multirow[t]{2}{*}{$\mathrm{N}=967$} & \multicolumn{2}{|c|}{ Before Peak } & \multicolumn{2}{|c|}{ During Peak } & \multicolumn{2}{|c|}{ after Peak } & \multicolumn{2}{|c|}{ Difference: } \\
\hline & & Physical & Mental & Physical & Mental & Physical & Mental & Physical & Mental \\
\hline \multirow[t]{2}{*}{ Independent samples $\mathrm{T}$ test } & $\mathrm{F}$ & 0.155 & -2.052 & -0.927 & -1.124 & -0.081 & -2.122 & -2.51 & 0.098 \\
\hline & $\mathrm{P}$ & 0.877 & $0.040 *$ & 0.354 & 0.261 & $0.038 *$ & $0.034 *$ & $0.012 *$ & 0.922 \\
\hline
\end{tabular}

Table 5 Correlation between self-reported health status and perceived health benefit $(\mathrm{N}=967, *: \mathrm{P}<0.05)$

\begin{tabular}{|c|c|c|c|c|c|}
\hline \multirow[t]{2}{*}{ Physical Health } & & & \multicolumn{3}{|l|}{ Self-reported physical health status } \\
\hline & & & Before Peak & Current & Difference: current-before \\
\hline \multirow[t]{8}{*}{ perceived health benefit } & Before Peak & Pearson Correlation & $0.069 *$ & - & - \\
\hline & & Sig.(2-tailed) & 0.031 & - & - \\
\hline & During Peak & Pearson Correlation & - & 0.004 & - \\
\hline & & Sig.(2-tailed) & - & 0.903 & - \\
\hline & After Peak & Pearson Correlation & - & 0.03 & - \\
\hline & & Sig.(2-tailed) & - & 0.356 & - \\
\hline & Difference: after-before & Pearson Correlation & - & - & -0.004 \\
\hline & & Sig.(2-tailed) & - & - & 0.91 \\
\hline \multirow[t]{2}{*}{ Mental Health } & & & Self-reported mental health status & & \\
\hline & & & Before Peak & Current & Difference: current-before \\
\hline \multirow[t]{8}{*}{ Perceived health benefit } & Before Peak & Pearson Correlation & 0.062 & - & - \\
\hline & & Sig.(2-tailed) & 0.055 & - & - \\
\hline & During Peak & Pearson Correlation & - & -0.004 & - \\
\hline & & Sig.(2-tailed) & - & 0.893 & - \\
\hline & After Peak & Pearson Correlation & - & 0.006 & - \\
\hline & & Sig.(2-tailed) & - & 0.85 & - \\
\hline & Difference: after-before & Pearson Correlation & - & - & -0.032 \\
\hline & & Sig.(2-tailed) & - & - & 0.314 \\
\hline
\end{tabular}

and perceived health benefits. This study is a general analysis based on national sampling. It does not provide a detailed analysis of specific WPs, including their quality, area, and naturalness. To control the number of questions and response time, this study did not use more detailed assessment scales (e.g. EQ-5D (Leidl 2009), General Health Questionnaire (White et al. 2013)) to assess health status. This could have an influence on the respondents' self-reported health status. Most participants had a high level of education, suggesting that they understand the contents of the questionnaire well. Due to the restrictions in face-to-face survey and the suspended express delivery in high-epidemic-risk regions during the pandemic, face-to face and mail surveys were not applicable. Besides, telephone surveys were usually rejected as fraudulent calls. Thus, this study relies on the online survey which was the most feasible method for collecting as many data from all over the country as possible within a very short period of time, potentially making it difficult for the elderly and non-internet users to get involved.

\section{Conclusion}

This research gives an overview of the perceived health effects of WPs in the context of COVID-19 in China to contribute to existing knowledge of health benefits of urban blue and green spaces and the link between ESs and human health. This study confirms that most people can perceive the health benefits of WPs. A slightly higher level of perceived health benefits after the Peak than before indicates that limited access to WPs increases perceived health benefits. Whilst very high epidemic risks might be said to have a negative impact on perceived physical health benefits, and lower risks may not be conducive to perceived mental health benefits, the moderate epidemic risk seems to be associated with greater physical and mental health benefits for visiting WPs during the Peak. Also, quarantine did not lead to an increase in health-related motivation for visiting WPs. Interestingly, health experts perceived lower health benefits than laypeople. At the same time, habitat services, which were regarded as indirect health-related 
ES, were perceived as the most crucial ES for promoting the perceived health benefits in WPs. Overall, a better understanding of the perception of health benefits of WPs can help to provide empirical evidence about ecosystem services as delivered by WPs, or green and blue space in general, in the context of COVID-19 and also regarding potential future pandemics.

Abbreviations WPs: Wetland parks; ESs: Ecosystem services; Peak: The peak of the COVID-19 pandemic

Acknowledgements We would like to thank the respondents of the survey.

Authors' Contributions $\mathrm{XZ}$ conceived and designed the study, collected and analysed data, and drafted the initial stages of the manuscript, with input and guidance of EL. EL commented on and provided revisions of the manuscript.

Funding This study is associated with the Adaptive Urban Transformation project (No. EP/R024979/1), funded by the Newton Fund and Engineering and Physical Sciences Research Council (EPSRC).

Availability of Data and Materials The datasets generated and/or analysed during the current study are available in the Figshare repository, https://figshare.com/s/3fb0f4d39f6459c4bba7

Code Availability Not applicable.

\section{Declarations}

Ethics Approval and Consent to Participate The questionnaire was limited to adults, ${ }^{4}$ filled out voluntarily, and no payment was made to the respondents. The questionnaire has been approved by the ethics panel of the University of Sheffield, reference number 030448. All participants included in this study gave written consent to participate in this research. All participants were adults.

Consent for Publication Not applicable.

Conflict of Interest/Competing Interest The authors declare that they have no competing interests.

Open Access This article is licensed under a Creative Commons Attribution 4.0 International License, which permits use, sharing, adaptation, distribution and reproduction in any medium or format, as long as you give appropriate credit to the original author(s) and the source, provide a link to the Creative Commons licence, and indicate if changes were made. The images or other third party material in this article are included in the article's Creative Commons licence, unless indicated otherwise in a credit line to the material. If material is not included in the article's Creative Commons licence and your intended use is not permitted by statutory regulation or exceeds the permitted use, you will need to obtain permission directly from the copyright holder. To view a copy of this licence, visit http://creativecommons.org/licenses/by/4.0/.

\footnotetext{
${ }^{4}$ The question of age was at the beginning of the questionnaire. If the respondent chose "below 18 years old", the questionnaire would skip to the end, and the questionnaire would be deemed invalid and deleted directly from the system.
}

\section{References}

Bowler DE, Buyung-Ali LM, Knight TM, Pullin AS (2010) A systematic review of evidence for the added benefits to health of exposure to natural environments. Public Health 10(456)

Bryman A (2012) Social research methods, fourth. Oxford University Press

Chinese Society of Landscape Architecture (CHSLA) (2020) Chengshi Yuanlin Lyudi Yingdui Xinguan Feiyan Yiqing Yunxing Guanli Zhinan (Guide to operation and management of urban green spaces in the context of COVID-19)(T/CHSLA10002-2020)

Crouse DL, Balram A, Hystad P, Pinault L, van den Bosch M, Chen H, Rainham D, Thomson EM, Close CH, van Donkelaar A, Martin RV, Ménard R, Robichaud A, Villeneuve PJ (2018) Associations between living near water and risk of mortality among Urban Canadians. Environmental Health Perspectives 126(7):77008. https://doi.org/10.1289/EHP3397

Dallimer M, Irvine KN, Skinner AM, Davies ZG, Rouquette JR, Maltby LL, Warren PH, Armsworth PR, Gaston KJ (2012) Biodiversity and the feel-good factor: understanding associations between self-reported human well-being and species richness. BioScience 62(1):47-55

de Vries S, Verheij RA, Groenewegen PP, Spreeuwenberg P (2003) Natural environments-healthy environments? An exploratory analysis of the relationship between greenspace and health. Environment and Planning 35:1717-1731

Ekkel ED, de Vries S (2017) Nearby green space and human health: evaluating accessibility metrics. Landscape and Urban Planning 157:214-220

Hartig T, Mitchell R, de Vries S, Frumkin H (2014) Nature and health. Annual Review of Public Health 35:207-228. https://doi.org/10. 1146/annurev-publhealth-032013-182443

Hazra A (2017) Using the confidence interval confidently. Journal of Thoracic Disease 9(10):4125-4130. https://doi.org/10.21037/jtd. 2017.09.14

Helbich M, Klein N, Roberts H, Hagedoorn P, Groenewegen PP (2018) More green space is related to less antidepressant prescription rates in the Netherlands_A Bayesian geoadditive quantile regression approach. Environmental Research 166:290-297

Horwitz P, Finlayson C (2011) Wetlands as settings for human health: incorporating ecosystem services and health impact assessment into water resource management. BioScience 61(9):678-688

Lachowycz K, Jones AP (2011) Greenspace and obesity: a systematic review of the evidence. Obesity Reviews: an Official Journal of the International Association for the Study of Obesity 12(5):e183e189. https://doi.org/10.1111/j.1467-789X.2010.00827.x

Leidl R (2009) Preferences, quality of life and public health. European Journal of Public Health 19(3):228-229

Lemieux CJ, Eagles PF, Slocombe DS, Doherty ST, Elliott SJ, Mock SE (2012) Human health and well-being motiatioins and benefits associated with protected area experiences: an opportunity for transforming policy and management in Canada. Parks 18:1

Lovell R, Wheeler BW, Higgins SL, Irvine KN, Depledge MH (2014) A systematic review of the health and well-being benefits of biodiverse environments. Journal of Toxicology and Environmental Health Part B 17(1):1-20. https://doi.org/10.1080/10937404.2013.856361

Luck GW, Davidson P, Boxall D, Smallbone L (2011) Relations between urban bird and plant communities and human well-being and connection to nature. Conservation Biology : the Journal of the Society for Conservation Biology 25(4):816-826. https://doi. org/10.1111/j.1523-1739.2011.01685.x

Maller C, Townsend M, Leger LS, Henderson-Wilson C, Pryor A, Prosser L, Moore M (eds) (2010) Healthy parks healthy people: The health benefits of contact with nature in a park context: A Review of Relevant Literature, 2nd edn 
Ministry of Housing and Urban-Rural Development of the Peoplers Republic of China (MOHURD) (2017) Chengshi Lyudi Fenlei Biaozhun(CJJ/T85-2017)

Ni Z, Lebowitz ER, Zou Z, Wang H, Liu H, Shrestha R, Zhang Q, Hu J, Yang S, Xu L, Wu J, Altice FL (2020) Response to the COVID-19 Outbreak in Urban Settings in China. Journal of Urban Health : Bulletin of the New York Academy of Medicine. https://doi.org/ 10.1007/s11524-020-00498-8

Olafsdottir G, Cloke P, Vögele C (2017) Place, green exercise and stress: An exploration of lived experience and restorative effects. Health \& Place 46:358-365. https://doi.org/10.1016/j.healthplace.2017.02.006

Oosterbroek B, de Kraker J, Huynen MM, Martens P (2016) Assessing ecosystem impacts on health: a tool review. Ecosyst Serv 17:237254. https://doi.org/10.1016/j.ecoser.2015.12.008

Orban E, Sutcliffe R, Dragano N, Jöckel K-H, Moebus S (2017) Residential Surrounding greenness, self-rated health and interrelations with aspects of neighborhood environment and social relations. Journal of Urban Health : Bulletin of the New York Academy of Medicine 94(2):158-169. https://doi.org/10.1007/s11524-016-0112-3

Richardson EA, Pearce J, Mitchell R, Kingham S (2013) Role of physical activity in the relationship between urban green space and health. Public Health 127:318-324

Romagosa F, Eagles PF, Lemieux CJ (2015) From the inside out to the outside in: Exploring the role of parks and protected areas as providers of human health and well-being. Journal of Outdoor Recreation and Tourism 10:70-77. https://doi.org/10.1016/j.jort.2015.06.009

Scholte SSK, Todorova M, van Teeffelen AJA, Verburg PH (2016) Public support for wetland restoration: what is the link with ecosystem service values? Wetlands 36(3):467-481. https://doi.org/ 10.1007/s13157-016-0755-6
Sutton-Grier AE, Sandifer PA (2019) Conservation of wetlands and other coastal ecosystems: a commentary on their value to protect biodiversity, reduce disaster impacts, and promote human health and well-being. Wetlands 39(6):1295-1302. https://doi.org/10. 1007/s13157-018-1039-0

Wang H, Dai X, Wu J, Wu X, Nie X (2019) Influence of urban green open space on residents' physical activity in China. BMC Public Health 19(1):1093. https://doi.org/10.1186/ s12889-019-7416-7

Wang L, Sun W, Wu Y (2020) Zhuguan Ganzhi de Chengshi Huanjing dui Jumin Jiankang de Yingxiang Yanjiu: Jiyu Quanguo 60 ge Xian Shi de Dayangben Diaocha (Study on the Impact of Subjective Perception of Urban Environment on Residents' Health: Based on a Large Sample Survey of 60 Counties and Cities in China). Human Geography(2):55-64

White MP, Alcock I, Wheeler BW, Depledge MH (2013) Coastal proximity, health and well-being: results from a longitudinal panel survey. Health Place 23:97-103. https://doi.org/10.1016/j.healt hplace.2013.05.006

Zhai X, Lange E (2020) Using Social Media to Explore Perceptions on Ecosystem Services by Nature-based Solution Projects. Landscape Architecture Frontiers 8(3):58-77. https://doi.org/10. 15302/J-LAF-1-020030

Zou S (2020) China passes outbreak climax as new cases keep declining. ChinaDaily

Publisher's Note Springer Nature remains neutral with regard to jurisdictional claims in published maps and institutional affiliations. 